TẠP CHÍ KHOA HỌC ĐẠI HỌC TÂN TRÀO

ISSN: 2354 - 1431

http://tckh.daihoctantrao.edu.vn/

\title{
So sánh thể thơ trong dân ca trữ tình sinh hoạt của người Tày và người Thái
}

\author{
Hà Xuân Hương ${ }^{a^{*}}$ \\ ${ }^{a}$ Trưòng Đại học Khoa học Thái Nguyên \\ *Email: haxuanhuong_dhkh@yahoo.com.vn
}

\section{Thông tin bài viết}

Ngày nhận bài:

$15 / 4 / 2018$

Ngày duyệt đăng:

$12 / 6 / 2018$

Tù khoá:

Thể tho; dân ca trũ tình sinh hoạt, người Tày, người Thái, so sánh.

\section{Tóm tắt}

Người Tày và người Thái sử dụng các thể thơ chủ đạo khác nhau khi sáng tác dân ca trữ tình sinh hoạt. Trong dân ca trữ tình sinh hoạt Tày, thể thơ thất ngôn chiếm ưu thế. Luợn cọi, luợn then, phong slu được sáng tác theo thể thất ngôn kéo dài. Luợn sluơng dùng thất ngôn tứ tuyệt nên nổi bật ở tính ngắn gọn. Việc sử dụng thể thất ngôn liên quan tới những ảnh hưởng của văn hóa Kinh, Hán tới văn hóa Tày thông qua con đường sách vở, học hành. Bên cạnh đó, người Thái sử dụng thể thơ tự do cho toàn bộ sáng tác dân ca trữ tình sinh hoạt của mình. Hai kiểu khống khái và $x u$ bắc được sử dụng xen kẽ trong bài hát nhằm tạo sự chuyển ý, chuyển đoạn uyển chuyển. Việc sử dụng phổ biến thể thơ này có.

\section{1. Đặt vấn đề}

Dân ca trữ tình sinh hoạt của người Tày và người Thái đều rất phong phú và đặc sắc. Nếu người Tày có luợn cọi (hát gọi bạn yêu), luợn sluơng (hát thương yêu), phong slu (thư tình)... thì người Thái có khắp báo xao (hát trai gái), khắp xai peng (hát dây tình), khắp hạn khuống (hát nơi sàn chơi), khắp loong tôông (hát nơi cánh đồng)... Sự gắn bó của dân ca trữ tình sinh hoạt với các đặc điểm địa - văn hóa, sử - văn hóa, ngôn ngữ... khiến cho nó thể hiện khá rõ ràng bản sắc văn hóa tộc người. Vì thế, một sự so sánh thể tho trong dân ca trữ tình sinh hoạt của hai dân tộc Tày, Thái sẽ góp phần chỉ ra tính chung của văn hóa các dân tộc, đồng thời khám phá tính đặc thù dân tộc của văn hóa người Tày và người Thái.

\section{Kết quả nghiên cứu và khảo sát}

\subsection{Thể thất ngôn trong dân ca trũ tình sinh} hoạt Tày

Dân ca trữ tình sinh hoạt Tày sử dụng các thể tự do, thể ngũ ngôn, thể thất ngôn. Trong đó, thể thơ chính là thể thất ngôn. Người Tày dùng cả thất ngôn tứ tuyệt, thất ngôn kéo dài (thất ngôn liên tục) và song thất. Theo kết quả khảo sát của chúng tôi, từ 1465 lời dân ca trữ tình sinh hoạt thống kê từ các công trình sưu tầm, biên dịch:
- Tổng tập văn học dân gian các dân tộc thiểu số Việt Nam, tập 18 - Dân ca [12].

- Tổng tập văn học dân gian các dân tộc thiểu số Việt Nam, tập 19 - Dân ca [13].

- Chồm bjoóc mạ [3].

- Lượn Tày: Lượn Tày Lạng Sơn, lượn slương [7].

- Phong slư [2].

- Thành ngữ, tục ngữ, ca dao dân tộc Tày [1].

thì có đến 1275 lời (chiếm $87 \%$ ) được làm theo thể thơ thất ngôn. Các thể khác chiếm tỉ lệ ít: Thể tự do chiếm 187 lời (12.8\%), thể ngũ ngôn chiếm 3 lời $(0.2 \%)$.

Người Tày có luợn cọi, luợn then, phong slu, luợn sluoong... đều là những loại hình dân ca giao duyên và được sáng tác theo thể thất ngôn. Trong đó, lươn cọi, luợn then, phong slu... được sáng tác theo thể thất ngôn kéo dài. Đây là thể thơ sử dụng vần chân (chữ cuối của câu trên vần với chữ lưng của câu dưới, thường là chữ thứ năm). Cách gieo vần này tương tự cách gieo vần trong câu song thất thuộc thể thơ song thất lục bát của người Việt. Người Việt gieo vần yêu vận ở hai câu thất của bài ca dao làm theo thể song thất lục bát:

Nước hồ Tây vìa trong vì̀a mát

Đuờng chộ Bưởi lắm cát dễ đi

Cô kia bóng bảy làm chi 
Để cho anh ấy đi đi về về.

[11, tr. 180]

Trong thể thất ngôn kéo dài của dân ca trữ tình sinh hoạt Tày, từ hai câu đầu gieo yêu vận, các câu thơ tiếp theo cứ theo quy luật này mà lặp lại. Từ đó, bài dân ca có thể dễ dàng kéo dài.

Buơn chiêng ngòi hăn bjoóc một than

Mọi thức bjoóc phung ban tềnh cáng

Ong điệp bên vội váng tím xa

Một mèng bên pây mà tím nhị

Nhu là than noọng nhỉ bấu hăn...

[8, tr. 206]

(Tháng giêng trồng hoa nở là than

Mọi thứ hoa ban nở trên cành

Ong buớm bay rộn ràng tìm thăm

Kiến ong cũng vội vàng tìm nhi

Nhu đang tìm bạn nghĩa mất đâu...)

$[8$, tr. 522]

Tuy thế, cần lưu ý lí do chính để các bài luợn cọi, phong slu, luợn sử... có dung lượng lớn không hoàn toàn do việc sử dụng thể thất ngôn kéo dài. Trên thực tế, các thể lục bát, song thất lục bát... phổ biến trong dân ca của người Kinh cũng có thể được sử dụng để gia tăng dung lượng của tác phẩm. Thế nhưng, ở dân ca của người Kinh chúng ta ít gặp trường hợp bài dân ca dài quá 20 câu. Sự khác nhau giữa độ dài của lượn cọi, lượn then... của người Tày so với dân ca của người Kinh lúc này không phụ thuộc vào thể thơ. Cụ thể, độ ngắn của dân ca của người Kinh phụ thuộc đặc điểm của lối hát đối đáp. Đối đáp là một hình thức tỏ tình của nam nữ thanh người Kinh. Đặc trưng của lối hát đối đáp là ngắn gọn. Tài năng của người đối đáp không phụ thuộc độ dài ngắn mà phụ thuộc vào khả năng ứng tác nhanh, nội dung sâu sắc. Trong khi đó, ở người Tày, ngoài hình thức đối đáp nhằm thể hiện tài năng của người hát, dân ca trữ tình sinh hoạt Tày còn có một bộ phận không liên quan đến tính chất thi tài giữa các bên hát. Chẳng hạn, luợn sủ liên quan tới việc mượn các tích truyện xưa cũ trong lịch sử, truyền thuyết... để nhắc nhở bạn tình noi theo, hoặc phong slu liên quan tới sự bộc lộ tình cảm buồn nhớ triền, luợn cọi tuy là đối đáp nhưng không đặt mục đích thi tài mà đề cao tính trình tự của nội dung hát. Chính vì thế, luợn sử, phong slu, luợn cọi thường khá dài.

Như vậy, độ dài của bài dân ca trữ tình sinh hoạt vì lí do sử dụng thể thất ngôn liên tục mà chúng tôi nghiên cứu ở đây chỉ có ý nghĩa phân biệt với độ ngắn của thể bài dân ca trữ tình sinh hoạt do được làm theo thể thất ngôn tứ tuyệt mà chúng tôi sẽ phân tích ở sau.

Vì được làm theo thể thất ngôn kéo dài nên nhiều bài dân ca trữ tình sinh hoạt của người Tày có dung lượng khá lớn. Chẳng hạn như cung lượn 12 tháng (slip nhí bươn) dài 249 câu. Các bài lượn còn có thể dài hơn thế, tùy thuộc vào nội dung và tài nghệ của những người tham gia vào cuộc lượn.

Trong luợn cọi, thỉnh thoảng có những bài mà có câu chỉ gồm 5 tiếng, kiểu biến thể. Lúc này, việc gieo vần cuối của câu trước sẽ rơi vào bất kì tiếng nào của câu tiếp. Như thế, vẫn là gieo yêu vận nhưng chữ lưng không cố định là tiếng thứ mấy, chỉ trừ tiếng cuối cùng. Chẳng hạn:

\section{Hua cắm moóc tỏa bản \\ Cần tồn mì lục nhạn mà nòn... \\ $[8$, tr. 14] \\ (Đầu hôm mây che bản}

Đồn rằng có con nhạn qua đêm...)

[8, tr. 322]

Kiểu gieo yêu vận như trên còn được áp dụng trong thể song thất của dân ca trữ tình sinh hoạt Tày, tương tự như thể song thất trong dân ca của người Kinh. Bên cạnh đó, thể tự do cũng dùng lối gieo vần yêu vận. Các thể này đều chiếm tỉ lệ rất nhỏ trong dân ca trữ tình sinh hoạt Tày.

Khác với luợn cọi, luợn then, phong slu là loại dân ca sử dụng vần lưng để kéo dài khổ thơ, lươn sluơng chỉ dùng loại thất ngôn tứ tuyệt là chính. Các câu 1, 2 , 4 vần với nhau như lối thơ Đường cổ xưa. Do thể thất ngôn tứ tuyệt có sự quy định rõ ràng về số câu trong một bài nên ở bài dân ca luợn sluơng luôn chỉ gồm 4 câu, không có sự kéo dài tùy hứng như lươn cọi, phong slu...

Cáy khăn liểu oóc tiểng cáy khăn

Lo tềnh nua pha oóc rụng vằn

Bạn hợi nhằng thwơng rà hại lỉn

Xiết hại sloong rà thuoong chứ căn.

[7, tr. 303]

(Gà gáy đi dạo gà gáy ran

Sợ trời cao rạng sáng mênh mang

Bạn có lòng thuoóng thời chơ đã

Kẻo nũa hai ta lại nhó than)

[7, tr. 435]

Việc sử dụng thể thất ngôn này có liên quan đến đội ngũ sáng tác dân ca Tày, bao gồm các nghệ nhân có tài, các trí thức bình dân của dân tộc. Ở từng vùng, nổi lên vai trò của các nghệ nhân dân gian nổi tiếng. Chẳng hạn, ở thôn Đồng Uẩn, xã Phúc Chu, huyện Định Hóa, tỉnh Thái Nguyên có nghệ nhân Lưu Xuân Lai, ở xã Hưng Khánh, huyện Trấn Yên, tỉnh Yên Bái có nghệ nhân Hoàng Kế Quang, ở xã Tân An, huyện Chiêm Hóa, tỉnh Tuyên Quang có nghệ nhân Hà Phan, Hà Thuấn... Họ là những người biết nhiều, giỏi sử 
dụng và sáng tác dân ca. Họ có vai trò to lớn trong việc trau dồi vần điệu của dân ca để tạo nên thể thơ với quy cách vần điệu ngày càng ổn định.

Việc dân ca trữ tình sinh hoạt Tày được sáng tác theo thể thất ngôn là chủ yếu có liên quan tới nguồn gốc và địa bàn cư trú của tộc người này. Trong lịch sử hình thành và phát triển của mình, người Tày ở Đông Bắc hiện nay bao gồm một bộ phận người có nguồn gốc là người Kinh hóa Tày. Bên cạnh đó, do đặc điểm vùng đất cư trú, người Tày cộng cư và cận cư với người Kinh. Những điều đó dẫn tới sự giao lưu, tiếp biến văn hóa giữa hai cộng đồng Kinh, Tày. Đây là cơ sở dẫn tới những ảnh hưởng nhất định đến việc sáng tạo văn học nghệ thuật. Một trong những ảnh hưởng đó là việc thể thơ thất ngôn được sử dụng rộng rãi trong dân ca trũ̃ tình sinh hoạt. Với việc sử dụng thể thơ này, dân ca trũ tình sinh hoạt Tày tiến dần tới sự chuyên nghiệp hóa.

\subsection{Thể tự do trong dân ca trũ tình sinh hoạt Thái}

Thể thơ chiếm ưu thế trong dân ca trữ tình sinh hoạt Thái là thể tự do, còn gọi là trúc chi từ. Lời hát gồm nhiều câu dài ngắn khác nhau, không nhất thiết theo một khuôn phép nào. Nhờ thế, câu hát trở nên mượt mà, phóng khoáng. Cảm xúc của con người được diễn đạt tự nhiên, trôi chảy như một dòng sông, không bị ngắt quãng hay chịu sự chi phối của các niêm luật gò bó. Cảm xúc cứ thế mở ra theo mạch kể. Câu trước gọi câu sau như dòng chảy mãi không ngừng. Câu hát tưởng hết lại có câu hát kế tiếp. Thể thơ này tạo cho dân ca trữ tình sinh hoạt Thái giống như những lời nhắn nhủ thiết tha, yêu thương nói mãi không hết, kể mãi không ngừng.

Thể tự do của dân ca trữ tình sinh hoạt Thái được biểu hiện thông qua các kiểu thông dụng như kiểu $x u$ bắc (câu dài 5 - 15 chữ, phải là số lẻ, ăn vần ở tiếng lẻ), khống khái (câu gồm 5 - 7 chữ, có vần giống nhu vè ở người Việt, vần đặt ở cuối câu trước, bắt vần với tiếng đầu câu sau). Các kiểu này dùng xen kẽ trong các bài hát và được chuyển đoạn, chuyển thể một cách điêu luyện, tài tình. Chẳng hạn, khi muốn chuyển tiếp giữa hai đoạn thơ gồm toàn những câu $5-7$ chữ, người ta sử dụng một vài câu thơ dài trên chục chữ, hoặc ngược lại, chen giữa hai đoạn thơ gồm toàn những câu dài trên chục chữ là những dòng thơ $5-7$ chữ, có khi co lại chỉ còn vài chữ. Cách chuyển đoạn uyển chuyển này không làm trở nhịp điệu của lời hát.

Để tạo nhịp điệu, các bài ca thường sử dụng vần lưng. Vần cuối của câu trước bắt với vần lưng của câu sau. Đáng chú ý là dân ca trữ tình Thái hiệp vần khá linh hoạt. Vần lưng có thể gieo vào tiếng bất kì của câu sau. Chỗ gieo vần lưng sẽ tạo ra nhịp ngắt. Nhờ đó, câu hát vừa vang $\mathrm{xa}$, vừa rung động như xoáy sâu vào trái tim người nghe. Dưới đây là một ví dụ cụ thể về thể trúc chi từ:

\section{Ài dặc nhăm phuc, cố phục hạt}

Nhăm xạt, cốxạt móng

Nhăm chong, cố chong xầu

Ai cu xó ê nộc xấu tù ô nọi họng dủ cho khú

Xó ê mu chúc xàng chụ khứa po tửn.

(Anh dẫm vào chiếu, sợ chiếu rách

Dẫm vào thảm, sọ thảm nhàu

Dẫm lên gixờng, sợ giuòng sập

Anh xin làm con cu gáy nhỏ gọ trong đêm

Xin lấy tay chạm sườn người tình của ai, đánh thức)

[13, tr. 951]

Rõ ràng, so với thể thất ngôn của người Tày, thể tự do của người Thái có một lợi thế để thể hiện những cung bậc cảm xúc của nhân vật trữ tình, đặc biệt trong tình cảm lứa đôi, các lứa đôi Thái sẽ không bị áp lực về quy tắc thể loại mà có thể thoải mái hát lên những cảm xúc chân thực nhất của mình.

Biểu hiện rõ nhất của dạng thức này, từ kết quả khảo sát của chúng tôi, trong 296 bài dân ca trữ tình sinh hoạt được sưu tầm, giới thiệu trong các công trình:

- Truyện cổ và dân ca Thái vùng Tây Bắc Việt Nam [5].

- Dân ca Thái Lai Châu, Quyển 1: Chiêng xoong mố bók (mùa xuân mùa hoa) [10].

- Dân ca Thái Lai Châu, Quyển 2: Thơ và dân ca tình yêu của người Thái Mường So [9].

- Khắp sứ lam của người Thái đen xã Noong luống, huyện Điện Biên, tỉnh Điện Biên [4].

Thì cả 296 lời này đều được sáng tác theo thể tự do, tức chiếm tỉ lệ $100 \%$.

Việc phổ biến thể tự do trong dân ca trữ tình sinh hoạt Thái có nguyên nhân từ đặc trưng ngôn ngữ Thái. Theo những nghiên cứu của các nhà khoa học về sự thiên di của các ngành Thái ở Tây Bắc Việt Nam, đặc biệt qua hai cuốn sử thi của người Thái Đen: Quắm tố muoong và Táy pú xấc, vào khoảng thế kỷ IX đến XI ngành Thái Đen do Tạo Xuông và Tạo Ngần dẫn đường di cư từ Mường Ôm, Mường Ai đến Mường Lò cư trú và họ đã sáng tạo ra chữ viết để ghi lại những sinh hoạt văn hóa của mình. Chữ viết là phương tiện duy nhất để ghi chép các thông tin kinh tế, xã hội, văn hóa của dân tộc Thái. Và như thế, chữ Thái cổ đã trở thành di sản văn hóa của tộc người và nhân dân Thái 
Mường Lò. Chữ Thái cổ Mường Lò không có dấu ngắt câu, bởi vậy, các văn bản chủ yếu được viết bằng văn vần, có vần điệu như thơ, có nhạc điệu và tiết tấu rất cao để dễ đọc và dễ nhớ. Bởi vậy, dân ca trữ tình sinh hoạt Thái được sáng tác dưới dạng những câu dài ngắn đan xen, nhưng đặc biệt giàu vần điệu và dễ nhớ, dễ khắp.

\section{3. Đôi điều bàn luận}

Một điều đáng chú ý, xét về kết cấu vần luật trong dân ca, trừ thể thất ngôn tứ tuyệt của người Tày gieo cước vận ổn định ở các câu 1, 2, 4 như một thể thơ của văn học viết của người Kinh, người Hán, các thể còn lại của thơ thất ngôn trong dân ca trữ tình sinh hoạt của người Tày và người Thái đều gieo yêu vận. Đặc điểm này còn được bắt gặp trong dân ca của người Việt và người Choang như tác giả Kiều Thu Hoạch từng chỉ ra trong bài viết So sánh kết cấu vần luật trong ca dao của tộc nguời Choang ở Trung Quốc và trong ca dao cả tộc người Việt ở Việt Nam [6, tr. 468 484]. Ở bài viết đó, nhà nghiên cứu Kiều Thu Hoạch gọi hình thức hiệp vần đó là yêu cước vận (vần lưng chân). Tuy có sự khác nhau về cách gọi song nó vẫn chỉ chung một đặc điểm là chữ cuối của câu trên hiệp vần với chữ lưng của câu dưới như trong dân ca trữ tình sinh hoạt Tày, Thái. Có thể thấy, sự tương đồng này không phải do một mối quan hệ ảnh hưởng trực tiếp nào cả, chỉ có thể lí giải bằng sự tương đồng về cội nguồn văn hóa sâu xa của các dân tộc này. Người Tày, Thái, Việt, Choang xa xưa đều là cư dân thuộc khối Bách Việt có sự gặp gỡ về ý thức thẩm mĩ, thể hiện ra là sự giống nhau về việc sử dụng vần lưng để gieo vần trong một số thể thơ của dân ca. Sự so sánh này nói lên tính chung về văn hóa của khối Bách Việt, đồng thời gợi mở một hướng nghiên cứu về văn hóa Bách Việt ở nhiều phương diện khác nữa.

\section{Kết luận}

Rõ ràng, dân tộc Tày, Thái, với những đặc trưng ngôn ngữ riêng, lực lượng sáng tác riêng, chịu ảnh hưởng của những vi hệ văn hóa khác nhau nên tất yếu dẫn tới sự khác nhau về thể thơ như trên.Việc sử dụng phổ biến thể thất ngôn trong dân ca trữ tình sinh hoạt Tày hay thể tự do trong dân ca trữ tình sinh hoạt Thái chính là sự thể hiện của nhịp điệu tâm hồn riêng của từng dân tộc. Cuộc sống gắn bó với núi rừng hoang vu, tâm hồn người Thái mộc mạc, dân dã, theo đó dân ca của họ cũng phóng khoáng với việc sử dụng phổ biến thể thơ tự do để diễn tả một cách tự nhiên cảm xúc của mình. Trái dại, dân ca trữ tình sinh hoạt Tày sử dụng phổ biến thể thơ thất ngôn do ảnh hưởng của thơ ca Hán, Kinh.

\section{TÀI LIỆU THAM KHẢO}

1. Hoàng Triều Ân (chủ biên) (2014), Thành ngũu Tục ngũ - Ca dao dân tộc Tày, Nxb Văn hóa dân tộc, Hà Nội;

2. Phương Bằng (sưu tầm, phiên âm chữ Nôm và dịch) (2012), Phong slu, Nxb Văn hóa dân tộc, Hà Nội;

3. Hoàng Thị Cấp (sưu tầm và dịch) (1994), Chồm bjoóc mạ, Nxb Văn hóa dân tộc, Hà Nội;

4. Tòng Văn Hân (2012), Khắp sứ lam của nguời Thái đen xã Nông Luống, huyện Điện Biên, tỉnh Điện Biên, Nxb Thời đại, Hà Nội;

5. Nguyễn Văn Hòa (sưu tầm, biên dịch) (2001), Truyện cổ và dân ca Thái vìng Tây Bắc Việt Nam, Nxb Văn hóa dân tộc, Hà Nội;

6. Kiểu Thu Hoạch (2014), Văn hóa dân gian nguời Việt - Góc nhìn so sánh, Nxb Khoa học Xã hội, Hà Nội;

7. Hoàng Văn Páo (chủ biên) (2012), Luợn Tày: Luợn Tày Lang Sơn, luợn sluơng, Nxb Văn hóa dân tộc, Hà Nội;

8. Lục Văn Pảo (sưu tầm, phiên âm và dịch) (1991), Luợn cọi, Nxb Văn hóa dân tộc, Hà Nội;

9. Hà Mạnh Phong, Đỗ Thị Tấc (sưu tầm và dịch) (2012), Dân ca Thái Lai Châu, Quyển 2 - Tho và dân ca tình yêu của nguoòi Thái Muờng So, Nxb Văn hóa dân tộc, Hà Nội;

10. Đỗ Thị Tấc (sưu tầm và dịch) (2012), Dân ca Thái Lai Châu, Quyển 1 - Chiêng xoong mố bók (mùa xuân mùa hoa), Nxb Văn hóa dân tộc, Hà Nội;

11. Trung tâm Khoa học Xã hội và Nhân văn quốc gia (2002), Tổng tập Văn học dân gian nguời Việt, tập 15 - Ca dao, Nxb Khoa học Xã hội, Hà Nội;

12. Viện Nghiên cứu văn hóa (2007), Tổng tập văn học dân gian các dân tộc thiểu số Việt Nam, tập 18 Dân ca, Nxb Khoa học Xã hội, Hà Nội;

13. Viện Nghiên cứu văn hóa (2007), Tổng tập văn học dân gian các dân tộc, Tập 19 - Dân ca, Nxb Khoa học Xã hội, Hà Nội. 


\section{Compare forms of poetry in Thai and Tay's folk songs}

\section{Ha Xuan Huong}

\section{Article info}

Recieved:

15/4/2018

Accepted:

$12 / 6 / 2018$

Keywords:

Forms of poetry, folk

songs, Thai people, Tay

people, compare.

\begin{abstract}
The Tay and Thai people use different forms of poetry when composing folk songs. In the Tay folk songs, the rhyme poetry predominates. Luon coi, luon then, phong slu is created by the long speech. Luon sluong used in Quiet language should be prominent in the short. The use of canon refers to the influence of Kinh culture and Han culture to the Tay through books and study. In addition, Thai people use free verse for all their folk songs. Two types of khong khai and $\mathrm{xu}$ bac are used intermixed in the song to make the transition and transfer verse. The widespread use of this form of poetry has its roots in the Thai language. The difference in the use of poetic form is the expression of the individual soul rhythm of each nation.
\end{abstract}

